\title{
Correction to: Effect of Aging on the Corrosion Resistance of 2209 Duplex Stainless Steel Weldments
}

\author{
Donghoon Kang ${ }^{1} \cdot$ Nohoon $\mathrm{Kim}^{2} \cdot \mathrm{Haewoo} \mathrm{Lee}^{2}$
}

Published online: 27 February 2019

(c) The Korean Institute of Metals and Materials 2019

\section{Correction to: Metals and Materials International https://doi.org/10.1007/s12540-018-0206-4}

The article "Effect of Aging on the Corrosion Resistance of 2209 Duplex Stainless Steel Weldments", written by Donghoon Kang, Nohoon Kim, and Haewoo Lee, was originally published electronically on the publisher's internet portal (currently SpringerLink) on 02 November 2018 with open access.
With the author(s)' decision to step back from Open Choice, the copyright of the article changed on 27 February 2019 to (C) The Korean Institute of Metals and Materials 2018 and the article is forthwith distributed under the terms of copyright.

The original article has been corrected.

The original article can be found online at https://doi.org/10.1007/ s12540-018-0206-4.

Haewoo Lee

hwlee@dau.ac.kr

1 Technical Research Center, Hyundai Steel Co. Ltd., Dangin 31719, Republic of Korea

2 Department of Materials Science and Engineering, Dong-A University, Busan 49315, Republic of Korea 